\title{
Loss on Drying
}

National Cancer Institute

\section{Source}

National Cancer Institute. Loss on Drying. NCI Thesaurus. Code C134255.

The determination of the total change in weight of a material as a result of drying. It determines the moisture content of a sample 